\title{
Melatonin at the crossroads: Commentary on COVID and cognition
}

\author{
Constantine Kaniklidis* \\ Research Director, No Surrender Breast Cancer Foundation (NSBCF), USA
}

\begin{abstract}
In this commentary, we explore the frontier edge of the emerging potential role of the chronobiotic agent melatonin, in both the prevention and treatment, and in the amelioration of some of the newly identified pathological neurocognitive sequelae, of SARS-2-CoV infection (COVID-19 disease). In the process we review clinical evidence of benefit in these domains, suggesting the strong promise that melatonin appears to provide, with a highly favorable benefit/harm ratio of excellent tolerability, affordability and safety, and sufficiently compelling evidence of efficacy as to be actionable, in the here and now.
\end{abstract}

\section{Melatonin in SARS-2-CoV (COVID-19) disease}

The ubiquitous pineal indolamine molecule melatonin is a chronobiotic, playing a critical role in the regulation of the human circadian rhythm, and exhibiting pleiotropic activity via its wellestablished anti-inflammatory, antioxidant and free radical scavenger, antiapoptotic, and immunomodulatory properties, with potential cytoprotective, neuroprotective, nephroprotective, cardioprotective, anti-hypertensive, anti-nociceptive, and antiviral effects consequent to immunomodulation, with emerging evidence of benefit in neurocognitive disorders $[1,2]$, these latter two capabilities we discuss more fully below.

Given the epidemiologic observation of high levels of melatonin in children and the significant decline with advanced age that may in part contribute to the vulnerability and high lethality of SARS-2-CoV (COVID-19) infections in the elderly [3] in conjunction with modest impact in exposed children who exhibit appreciable relative resistance, and from the observation of its potential in recent previous Ebolavirus Disease (EVD) outbreaks starting in 2013 to limit or counter oxidative stress and immuno-inflammatory injury [4-8], there has been a strong burst of interest and research in the deployment of melatonin for the prevention and treatment of COVID-19 disease. This is motivated by its spectrum of established antiviral activities consequent to its suppression of multiple inflammatory pathways [9] and its strong immunostimulatory activity through production of multiple interleukins (IL$1 / 2 / 6 / 12)$, and of interferon $\gamma($ IFN- $\gamma)$, cytotoxic T cells, and B- and T-cell precursors among others, especially relevant against a disease COVID-19 whose pathophysiological hallmarks include excessive inflammation, oxidation, and an hyper-exaggerated immune response that can culminate in a "cytokine storm" and can progress to and trigger acute lung injury (ALI) / acute respiratory distress syndrome (ARDS) and multiple organ failures, such progression not infrequently proving fatal [10].

Melatonin's antiviral activities via the suppression of inflammatory pathways [9] is of special interest given the known pathophysiological lung characteristics of severe COVID-19 patients. Melatonin's mechanism of action may also help to explain the epidemiologic observation that children, who have naturally high melatonin levels, are relatively resistant to COVID-19 disease manifestations, whereas older individuals, who have decreasing melatonin levels with age, are a very high-risk population. In addition, exogenous melatonin administration / supplementation may be of particular benefit to older patients given the aging-related reduction of endogenous melatonin levels and the vulnerability of older individuals to the high lethality of SARS-CoV-2 [10].

In terms of clinical studies, based on these considerations a potential therapeutic regimen has been hypothesized for COVID-19 patients, $3-10 \mathrm{mg}$ for elderly and high-risk patients, escalated up to $40 \mathrm{mg}$ for health care workers, administered 30 to $60 \mathrm{~min}$ pre-bedtime [11], in substantial agreement with UT Texas San Antonio researchers in collaboration with CIBER de enfermedades CardioVasculares (CIBERCV) (Madrid). In addition, a retrospective descriptive case series at Manila Doctors Hospital (Manila, Philippines) of patients admitted with COVID19 pneumonia treated with high-dose melatonin at doses of $36-72 \mathrm{mg} /$ day in 4 divided doses as adjuvant therapy [12] found clinical stabilization and/or improvement within 4-5 days after initiation of high-dose melatonin in all patients treated with it, all surviving, (including 3 with moderately severe ARDS, 1 with mild ARDS), and with none requiring mechanical ventilation. The only adverse event was sleepiness which patients deemed favorable. This small $(n=10)$ case series suggests that melatonin may provide shorter time to clinical improvement, reduced need for mechanical ventilation, shorter hospital stay and possibly lower mortality. And a recent singlecenter, double-blind, randomized clinical trial of patients hospitalized with confirmed mild to moderate COVID-19 found that those who received standard of care plus melatonin dosed at $3 \mathrm{mg}$ three times daily for 14 days, when compared to the control group without melatonin, had significantly improved clinical symptoms (cough, dyspnea, and fatigue), more optimal levels of C-reactive protein (CRP), and reduced

${ }^{*}$ Correspondence to: Constantine Kaniklidis, Research Director, No Surrender Breast Cancer Foundation (NSBCF) ${ }^{\star}$ Member, Society for Integrative Oncology (SIO), USA, E-mail: edge@evidencewatch.com

Received: October 28, 2020; Accepted: November 20, 2020; Published: November 23, 2020 
pulmonary involvement, and with significantly shorter mean time of hospital discharge and return to baseline health [13].

\section{Melatonin - neurocognitive impact and issues}

Although we must grant that our knowledge of melatonin's complex kinetics and dynamics continues to evolve [14], nonetheless there is wide consensus on core functional, operational and molecular principles including those relating to neurocognitive activity, and given that melatonin binds to and exerts its biological / physiological activities through the high-affinity $G$ protein-coupled membrane receptors MT1 and MT2 expressed throughout the body, including in the central nervous system, and its biosynthesis is predominantly via the suprachiasmatic nucleus ( $\mathrm{SCN}$ ) with the limiting synthesis enzyme being the arylalkylamine $\mathrm{N}$-acetyl transferase (AANAT) $[15,16]$, there has been intense interest in melatonin's neurological mechanisms and potential benefits. In addition, melatonin synthesis is in part modulated by the brain renin-angiotensin system (RAS) that is critical in blood pressure regulation and in several cardiovascular disorders and in the pathogenesis of pulmonary diseases, and which is also implicated the complex pathologies of acute respiratory distress syndrome (ARDS) seen in COVID-19 disease, part of which can be countered via angiotensin converting enzyme (ACE) 2 (ACE2) activity that may attenuate inflammation [17]. We note in this connection that there have been questions raised as to the potentially adverse impact on the susceptibility to and severity of SARS-CoV-2 infection of ACE inhibitors (ACEIs) and AT1R blockers (ARBs) that are deployed in both pulmonary inflammatory and cardiovascular diseases, but more recent robust meta-analytic data fail to support this [18,19] although there is some suggestion there may be some geographic dependencies as to benefits versus harms [20].

In parallel, there is thus a growing literature documenting the potentially long-term neurocognitive sequelae / impairment that may be engendered by the neuroinflammatory cascade associated with COVID-19 [21-25] and in confirmation, recent postmortem findings have shown SARS-CoV-2 virus in neural tissue: in the cerebrospinal fluid (CSF) and in parts of the brain's frontal lobe [26-28].

Noting these potentially negative neurocognitive impacts of acute respiratory distress (ARD) and hypoxia, and especially the hyperelevated levels of proinflammatory cytokines released in COVID-19 infections, researchers at the University of Bonn, and others, have hypothesized that patients may experience post-infection cognitive decline [29], not altogether surprising given high rates of memory impairment reported in the aftermath of two previous coronavirus outbreaks, SARS in 2002 - 2003, and MERS in 2012 [21]. These concerns have led to the establishment of the international Consortium for Chronic Neuropsychiatric Sequelae of SARS-CoV-2, aka the "CNS SARS-CoV-2 Consortium", founded by The Alzheimer's Association and with representatives from $30+$ countries under technical guidance from the World Health Organization (W.H.O) [22]. Also recently launched is GCS-NeuroCOVID, the Global Consortium to Study Neurological dysfunction in COVID-19, under endorsement of the Neurocritical Care Society (NCS) that is focusing on the prevalence, pathophysiology and prognostic implications of neurological complications among hospitalized COVID-19 patients [30], with many others of comparable intent being formed at national and regional levels.

In light of the data supporting the underlying dysregulated neuroinflammatory processes engendered by SARS-CoV-2 infection, we note that melatonin has demonstrable cross-BBB (blood-brain barrier) capabilities, and benefits on both cognitive function and sleep quality
[31]. And although it is true that one meta-analysis of seven studies concluded that Alzheimer's Disease patients receiving melatonin therapy showed no improvement in cognitive abilities as assessed by the mini-mental state examination (MMSE) and the Alzheimer's Disease Assessment Scale-Cognition (ADAS-Cog) [32], we hazard this may in part have been due to the formulation, immediate release (IR) versus prolonged release (PR): in a randomized, placebo-controlled, multicenter trial using $2 \mathrm{mg}$ of prolonged release melatonin as adjunct to the existing treatment regimen for Alzheimer's Disease, there was in fact a statistical improvement in median ADAS-Cog values [33]. Furthermore, recent data supports the amelioration of neuroinflammation and of amyloid-beta protein (A $\beta$ )-induced neurotoxicity [31], which when diminished alleviates many of the pathological symptoms of Alzheimer's Disease [34,35]. Thus a recent study [36] explored the effect of six-months of melatonin therapy $(0.15$ $\mathrm{mg} / \mathrm{kg}$ ) on the thickness of the lamina cribrosa in patients with minimal cognitive impairment, finding significantly augmented thickness and hippocampal volume. CSF tau levels were reduced along with improvement in the mini mental score, compared to the untreated group, suggesting the efficacy to melatonin in the reduction of brain degeneration and its clear potential in the neurological sequelae of COVID-19.

In this connection, based on their recent review of the evidence, the Recommendations of the French Medical and Research Sleep Society (SFRMS) categorized as Level A results showing that melatonin as add-on treatment provides beneficial effects both in mild cognitive impairment (MCI), and in the improvement of sleep quality in Alzheimer patients [37]. Indeed, a randomized controlled trial found that $2 \mathrm{mg}$ of prolonged (time-released) melatonin in Alzheimer's Disease patients improved cognitive function with significant reversal of circadian disruption [33].

Tellingly, from a variety of malignancies, we know that chemotherapy is neurotoxic and that there are both acute and delayed adverse side effects of chemotherapy on cognitive function, with the resulting cognitive impairment a source of considerable distress, compromising the patient's QoL - with as much as $75 \%$ of breast cancer patients affected [38] in part mediated by oxidative stress associated with chemotherapy and by decreased hippocampal volume and cytokine-mediated blood brain barrier disruption [38-40], with some of these contributory neuroinflammatory cascades being triggered in many cases both by the cancer itself as well as the chemotherapy regimens deployed. It is important to note that optimal dosing matters, this being set at $20 \mathrm{mg}$ nightly [39], as witness an earlier RCT [41] that failed to find any effect of melatonin on cognitive function, but the difference being it dosed at $6 \mathrm{mg}$. In sum, a rich body of literature in oncology strongly supports $20 \mathrm{mg}$ as the optimal dosing level $[42,43]$.

Finally, we note that we have cross-discipline validation. Chemotherapy-related cognitive impairment in breast cancer patients receiving chemotherapy engenders both acute and/or delayed complications, with $52 \%$ of those treated experiencing peri- and post-treatment chemotherapy-related cognitive function decline (compared to just 23\% pre-chemotherapy) [44], these persistent cognitive deficits widely known among patients as "chemo-brain" or "chemo-fog", confirming the neurotoxicity of chemotherapy. A recent randomized, double-blind, placebo-controlled trial examined the effects of melatonin therapy on cognition, sleep, and depression in breast cancer chemotherapy patients, finding that melatonin, when dosed at $20 \mathrm{mg}$ nighttime before and during the first cycle of adjuvant chemotherapy in breast cancer patients exerts a neuroprotective effect on the neuroplasticity process, significantly offsetting the well-known 
phenomenon of chemotherapy-related cognitive function decline, as well as improving sleep quality and depressive symptoms compromised by chemotherapy exposure [45].

\section{Conclusions}

Given the continued relative scarcity of preventive agents as well as treatment regimens for SARS-2-CoV (COVID-19), and the staggering toll that this pandemic continues to exact across the globe, we are not sanguine that the current rather fitful rollout of COVID vaccines will be sufficient in the near term to control this wily and highly lethal (especially in vulnerable populations) infection, so there is a moral imperative to leverage available / repurposed tools like melatonin (and likely synergistically, Vitamin D3) that have demonstrable safety and tolerability, are affordable and easily accessible, and with provisional but strongly compelling evidence of efficacy that may serve as beneficial adjuncts in our continued efforts to stay the devastation that this disease continues to bring in its wake, especially so, but not only, in resourceconstrained regions of the world.

* The No Surrender Breast Cancer Foundation is a U.S.-based 501(c)3 not-for-profit organization providing high-quality critically reviewed and appraised information and guidance to the breast cancer community.

\section{References}

1. Posadzki PP, Bajpai R, Kyaw BM, Roberts NJ, Brzezinski A, et al. (2018) Melatonin and health: an umbrella review of health outcomes and biological mechanisms of action. BMC Med 16: 18. [Crossref]

2. Cipolla-Neto J, Amaral FGD (2018) Melatonin as a Hormone: New Physiological and Clinical Insights. Endocr Rev 39: 990-1028. [Crossref]

3. Cardinali DP, Brown GM, Reiter RJ, Pandi-Perumal SR (2020) Elderly as a Highrisk Group during COVID-19 Pandemic: Effect of Circadian Misalignment, Sleep Dysregulation and Melatonin Administration. Sleep Vigil: 1-7. [Crossref]

4. Tan DX, Korkmaz A, Reiter RJ, Manchester LC (2014) Ebola virus disease: potential use of melatonin as a treatment. J Pineal Res 57: 381-384. [Crossref]

5. Anderson G, Maes M, Markus RP, Rodriguez M (2015) Ebola virus: Melatonin as a readily available treatment option. J Med Virol 87: 537-543. [Crossref]

6. Reiter RJ, Ma Q, Sharma R (2020) Treatment of ebola and other infectious diseases: melatonin "goes viral". Melatonin Research 3: 43-57.

7. Wells AI, Coyne CB (2020) Inhibiting Ebola virus and SARS-CoV-2 entry. Science 370: 167-168. [Crossref]

8. Kaniklidis C (2016) Ebola Virus Disease (EVD): New Understandings and New Frontiers in Therapeutics. Unpublished draft. [https://www.academia.edu/9160716/ Ebola_Virus_Disease_EVD_New_Understandings_and_New_Frontiers_in Therapeutics]. Accessed 10 January 2021.

9. Carrillo-Vico A, Guerrero JM, Lardone PJ, Reiter RJ (2005) A review of the multiple actions of melatonin on the immune system. Endocrine 27: 189-200. [Crossref]

10. Wang D, Hu B, Hu C, Zhu F, Liu X, et al. (2020) Clinical characteristics of 138 hospitalized patients with 2019 novel coronavirus-infected pneumonia in Wuhan, China. JAMA 323: 1061-1069. [Crossref]

11. Reiter RJ, Abreu-Gonzalez P, Marik PE, Dominguez-Rodriguez A (2020) Therapeutic algorithm for use of melatonin in patients with COVID-19. Front Med (Lausanne) 7: 226. [Crossref]

12. Castillo RR, Quizon GRA, Juco MJM, Roman ADE, de Leon DG, et al. (2020) Melatonin as adjuvant treatment for coronavirus disease 2019 pneumonia patients requiring hospitalization (MAC-19 PRO): a case series. Melatonin Research 3: 297-310.

13. Farnoosh G, Akbariqomi M, Badri T, Bagheri M, Izadi M, et al. (2020) Efficacy of a Low Dose of Melatonin as an Adjunctive Therapy in Hospitalized Patients with COVID-19: A Randomized, Double-blind Clinical Trial. Authorea Preprints.

14. Boutin JA, Jockers R (2020) Melatonin controversies, an update. J Pineal Res: e12702. [Crossref]

15. Stauch B, Johansson LC, Cherezov V (2020) Structural insights into melatonin receptors. FEBS J 287: 1496-1510. [Crossref]
16. Liu J, Clough SJ, Hutchinson AJ, Adamah-Biassi EB, Popovska-Gorevski M, et al. (2016) MT1 and MT2 Melatonin Receptors: A Therapeutic Perspective. Annu Rev Pharmacol Toxicol 56: 361-383. [Crossref]

17. Hrenak J, Simko F (2020) Renin-Angiotensin System: An Important Player in the Pathogenesis of Acute Respiratory Distress Syndrome. Int J Mol Sci 21: 8038. [Crossref]

18. Guo X, Zhu Y, Hong Y (2020) Decreased mortality of COVID-19 with reninangiotensin-aldosterone system inhibitors therapy in patients with hypertension: A meta-analysis. Hypertension 76: e13-e14. [Crossref]

19. Barochiner J, Martínez R (2020) Use of inhibitors of the renin-angiotensin system in hypertensive patients and COVID-19 severity: A systematic review and meta-analysis. J Clin Pharm Ther 45: 1244-1252. [Crossref]

20. Patoulias D, Katsimardou A, Stavropoulos K, Imprialos K, Kalogirou MS, et al. (2020) Renin-Angiotensin System Inhibitors and COVID-19: A Systematic Review and MetaAnalysis. Evidence for Significant Geographical Disparities. Curr Hypertens Rep 22 90. [Crossref]

21. Rogers JP, Chesney E, Oliver D, Pollak TA, McGuire P, et al. (2020) Psychiatric and neuropsychiatric presentations associated with severe coronavirus infections: systematic review and meta-analysis with comparison to the COVID-19 pandemic. Lancet Psychiatry 7: 611-627. [Crossref]

22. de Erausquin GA, Snyder H, Carrillo M, Hosseini AA, Brugha TS, et al. (2021) The chronic neuropsychiatric sequelae of COVID-19: The need for a prospective study of viral impact on brain functioning. Alzheimers Dement. [Crossref]

23. Zhou H, Lu S, Chen J, Wei N, Wang D, et al. (2020) The landscape of cognitive function in recovered COVID-19 patients. J Psychiatr Res 129: 98-102. [Crossref]

24. Bougakov D, Podell K, Goldberg E (2020) Multiple Neuroinvasive Pathways in COVID-19. Mol Neurobiol 58: 564-575. [Crossref]

25. Steardo L Jr., Steardo L, Verkhratsky A (2020) Psychiatric face of COVID-19. Trans Psychiatry 10: 261. [Crossref]

26. Paniz-Mondolfi A, Bryce C, Grimes Z, Gordon RE, Reidy J, et al. (2020) Centra nervous system involvement by severe acute respiratory syndrome coronavirus-2 (SARS-CoV-2). J Med Virol 92: 699-702. [Crossref]

27. Lin E, Lantos JE, Strauss SB, Phillips CD, Campion TR Jr, et al. (2020) Brain Imaging of Patients with COVID-19: Findings at an Academic Institution during the Height of the Outbreak in New York City. AJNR Am J Neuroradiol 41: 2001-2008. [Crossref]

28. Romero A, Ramos E, López-Muñoz F, Gil-Martín E, Escames G, et al. (2020) Coronavirus Disease 2019 (COVID-19) and Its Neuroinvasive Capacity: Is It Time for Melatonin? Cell Mol Neurobiol 1-12. [Crossref]

29. Heneka MT, Golenbock D, Latz E, Morgan D, Brown R. (2020) Immediate and long-term consequences of COVID-19 infections for the development of neurological disease. Alzheimers Res Ther 12: 69. [Crossref]

30. Frontera J, Mainali S, Fink EL, Robertson CL, Schober M, et al. (2020) Global Consortium Study of Neurological Dysfunction in COVID-19 (GCS-NeuroCOVID): Study Design and Rationale. Neurocrit Care 33: 25-34. [Crossref]

31. Li Y, Zhang J, Wan J, Liu A, Sun J (2020) Melatonin regulates A $\beta$ production/clearance balance and $\mathrm{A} \beta$ neurotoxicity: A potential therapeutic molecule for Alzheimer's disease. Biomed Pharmacother 132: 110887. [Crossref]

32. Wang YY, Zheng W, Ng CH, Ungvari GS, Wei W, et al. (2017) Meta-analysis of randomized, double-blind, placebo-controlled trials of melatonin in Alzheimer's disease. Int J Geriatr Psychiatry 32: 50-57. [Crossref]

33. Wade AG, Farmer M, Harari G, Fund N, Laudon M, et al. (2014) Add-on prolongedrelease melatonin for cognitive function and sleep in mild to moderate Alzheimer's disease: A 6-month, randomized, placebo-controlled, multicenter trial. Clin Interv Aging 9: 947-61. [Crossref]

34. Shukla M, Govitrapong P, Boontem P, Reiter RJ, Satayavivad J (2017) Mechanisms of Melatonin in Alleviating Alzheimer's Disease. Curr Neuropharmacol 15: 1010-1031. [Crossref]

35. Vincent B. (2018) Protective roles of melatonin against the amyloid-dependent development of Alzheimer's disease: A critical review. Pharmacol Res 134: 223-237. [Crossref]

36. Xu L, Yu H, Sun H, Hu B, Geng Y (2020) Dietary Melatonin Therapy Alleviates the Lamina Cribrosa Damages in Patients with Mild Cognitive Impairments: A DoubleBlinded, Randomized Controlled Study. Med Sci Monit 26: e923232. [Crossref]

37. Vecchierini MF, Kilic-Huck U, Quera-Salva MA (2020) Members of the MEL consensus group of the SFRMS. Melatonin (MEL) and its use in neurological diseases and insomnia: Recommendations of the French Medical and Research Sleep Society (SFRMS). Rev Neurol (Paris) S0035-3787(20)30656-1. [Crossref] 
38. Wefel JS, Kesler SR, Noll KR, Schagen SB (2015) Clinical characteristics, pathophysiology, and management of noncentral nervous system cancer-related cognitive impairment in adults. CA Cancer J Clin 65: 123-38. [Crossref]

39. Wardill HR, Mander KA, Van Sebille YZA, Gibson RJ, Logan RM, et al. (2016) Cytokinemediated blood brain barrier disruption as a conduit for cancer/chemotherapy-associated neurotoxicity and cognitive dysfunction. Int J Cancer 139: 2635-2645. [Crossref]

40. Lv L, Mao S, Dong H, Hu P, Dong R (2020) Pathogenesis, Assessments, and Management of Chemotherapy-Related Cognitive Impairment (CRCI): An Updated Literature Review. J Oncol 2020: 3942439. [Crossref]

41. Hansen MV, Madsen MT, Andersen LT, Hageman I, Rasmussen LS, et al. (2014) Effect of Melatonin on Cognitive Function and Sleep in relation to Breast Cancer Surgery: A Randomized, Double-Blind, Placebo-Controlled Trial. Int J Breast Cancer 2014: 416531. [Crossref]
42. González A, Rueda Revilla N, Sánchez-Barceló E (2019) Clinical uses of melatonin: evaluation of human trials on cancer treatment. Melatonin Research 2: 47-69. [Crossref]

43. Wang Y, Wang P, Zheng X, Du X (2018) Therapeutic strategies of melatonin in cancer patients: a systematic review and meta-analysis. Onco Targets Ther 11: 7895-7908. [Crossref]

44. Jansen CE, Miaskowski C, Dodd M, Dowling G, Kramer J, et al. (2005) A metaanalysis of studies of the effects of cancer chemotherapy on various domains of cognitive function. Cancer 104: 2222-33. [Crossref]

45. Palmer ACS, Zortea M, Souza A, Santos V, Biazús JV, et al. (2020) Clinical impact of melatonin on breast cancer patients undergoing chemotherapy; effects on cognition, sleep and depressive symptoms: A randomized, double-blind, placebo-controlled trial PLoS One 15: e0231379. [Crossref]

Copyright: (C2020 Kaniklidis C. This is an open-access article distributed under the terms of the Creative Commons Attribution License, which permits unrestricted use, distribution, and reproduction in any medium, provided the original author and source are credited. 